Supplement of Clim. Past, 13, 991-1005, 2017

https://doi.org/10.5194/cp-13-991-2017-supplement

(C) Author(s) 2017. This work is distributed under

the Creative Commons Attribution 3.0 License.

(c) (1)

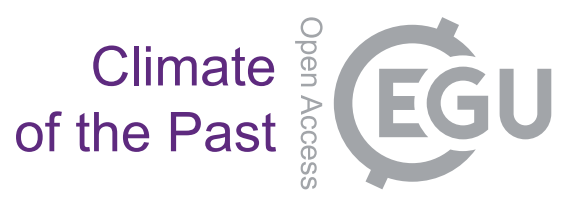

Supplement of

\title{
Post-glacial flooding of the Bering Land Bridge dated to 11 cal ka BP based on new geophysical and sediment records
}

Martin Jakobsson et al.

Correspondence to: Martin Jakobsson (martin.jakobsson@geo.su.se)

The copyright of individual parts of the supplement might differ from the CC BY 3.0 License. 


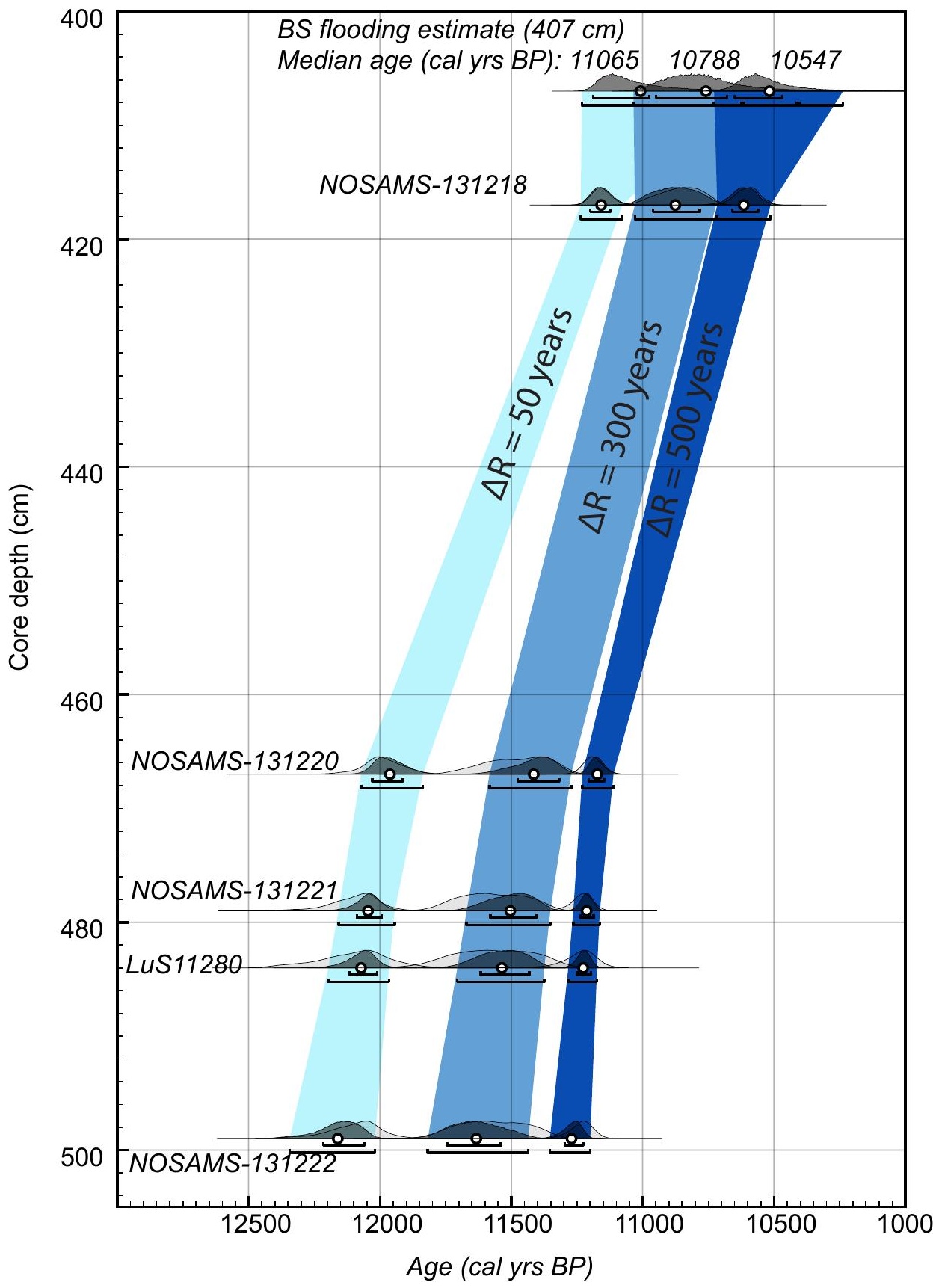

